Document de Recherche du Laboratoire d'Économie d'Orléans

Working Paper Series, Economic Research Department of the University of Orléans (LEO), France

DR LEO 2020-16

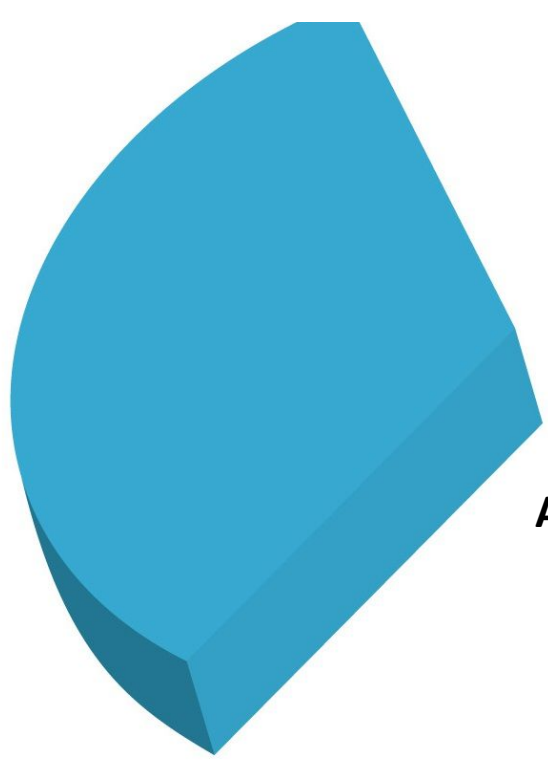

On the Exchange Rates Volatility and

Economic Policy Uncertainty Nexus:

A Panel VAR Approach for Emerging Markets

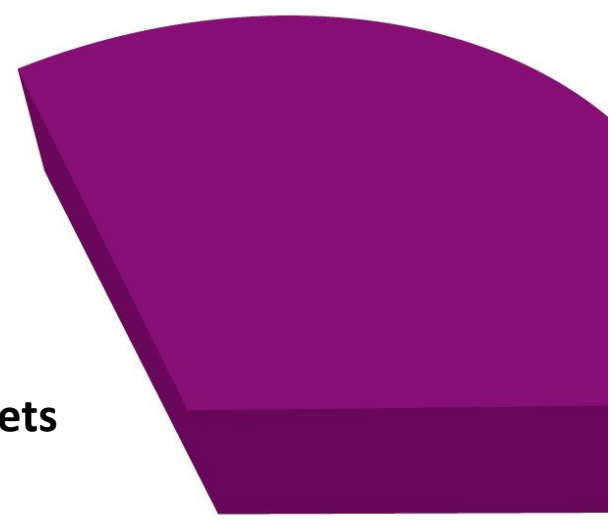

Abir ABID

Christophe RAULT

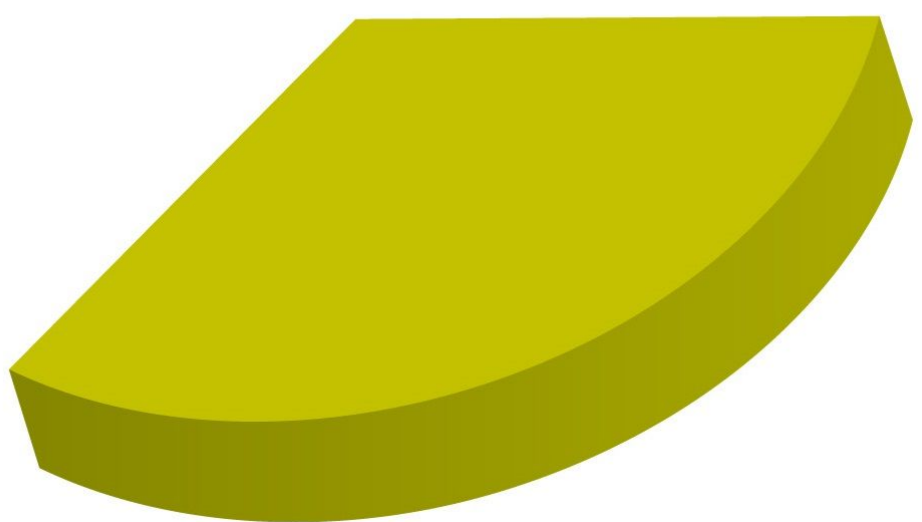

Mise en ligne / Online : 07/10/2020 


\title{
On the Exchange Rates Volatility and Economic Policy Uncertainty Nexus: A Panel VAR Approach for Emerging Markets
}

\author{
Abir Abid ${ }^{\mathrm{a}}$, and Christophe Rault ${ }^{\mathrm{b}}$ \\ a LEO, Université d'Orléans, CNRS, LEO, FRE 2014, F45067, Orléans, France et MACMA, \\ Institut Supérieur de Gestion de Tunis, Université de Tunis, Tunisie. \\ Email : abir.abid@etu.univ-orleans.fr/abir1988abid@gmail.com \\ ${ }^{\mathrm{b}}$ LEO, Université d'Orléans, CNRS, LEO, FRE 2014, F45067, Orléans, France \\ Corresponding author: E-mail address: chrault@hotmail.com \\ Web-site: http://chrault3.free.fr.
}

\begin{abstract}
We examine the Economic Policy Uncertainty (EPU) transmission over the Exchange Rate Volatility (ERV) for 8 Emerging Market Economies (EME) using the recent panel VAR methodology of Abrigo and Love (2016). The econometric investigation reveals that: (a) both domestic and US EPU shocks exert positive effects on the ERV, (b) the contribution of the US EPU to the ERV fluctuations overcomes the own EPU's share, (c) the ERV acts as a possible transmission channel of the US-EPU to the domestic economic activity, (d) the domestic EPU increases in response to a higher US EPU and vice versa and (e) the latter is surprisingly and markedly sensitive to EME macroeconomic conditions. Our findings are robust to different sensitivity analyses, provide novel insights into EPU international spillovers, and have interesting policy implications for EME decisions makers and investors.
\end{abstract}

Keywords: Emerging Market Economies, Economic Policy Uncertainty, Exchange Rates Volatility, Panel VAR.

JEL Classification : G15, E44, C22. 


\section{Introduction}

The predictive power of fundamentals on the exchange rate fluctuations remains one of the most discussed puzzles in international economics. While their long-run effects on currency movements are confirmed (Beckmann and Czudaj, 2017), their short-run impacts have much less empirical success (Chen and Chou, 2015) ${ }^{1}$. Nonetheless, the short-run exchange rate dynamics are particularly affected by transitory shocks including the economic policy uncertainty (EPU hereafter) (Bartsch, 2019). At a general level, a widely supported result of the applied literature is the harmful effects of the EPU on economic activity (Baker et al. 2016; Bloom, 2009) and asset prices (Pástor and Veronesi, 2012; Brogaard and Detzel, 2015; Arouri et al. 2016) ${ }^{2}$. Within this growing literature, the foreign exchange market (FOREX) reaction to the EPU is, to date, explored only by a handful of studies. Firstly, they predict that a surge in the EPU coincides with a national currency depreciation (Abid, 2019; Nilavongse, 2020) as well as a rise of the exchange rate volatility (ERV hereafter) (Chen et al. 2019; Bartsch, 2019; Christou et al. 2018, Balcilar et al. 2016). Secondly, the exchange rate appears more sensitive to the domestic rather than the foreign EPU (Nilavongse et al. 2020). From a technical point of view, these empirical exercises have had sustainable interest to time series frameworks mainly focusing on advanced economies ( $C f$. Bartsch, 2019; Nilavongse et al. 2020) or some major emerging markets such as China (Chen et al. 2019). Notable few exceptions are Balcilar et al. (2016) and Christou et al. (2018) who consider a mixture of developed and developing countries.

To complement this literature, our study primarily builds on the body of the research pioneered by Bloom (2009) in investigating the macroeconomic effects of uncertainty by examining how the ERV responds to both domestic and foreign EPU in Emerging Market Economies (EME). We contribute to the current debate in several ways. The first novelty is the exclusive focus on EME as a case study ${ }^{3}$. These countries (i) display a higher ERV especially those having adopted floating exchange regimes (ii) face higher levels of uncertainty comparing to advanced economies (Bloom, 2009) and (iii) are extremely vulnerable to shocks spillovers stemming from developed countries (Bhattarai et al. 2019). In addition, this paper aims at revealing the extent to which considering cross sectional dependence between countries can affect the

\footnotetext{
${ }^{1}$ The literature highlights a weak empirical performance of fundamentals in predicting exchange rates especially in the short run. See for instance the pioneer study of Meese and Rogoff, (1983).

${ }^{2}$ Note that a wide array of papers primarily concentrates on how stock prices behave in response to the EPU.

${ }^{3}$ Abid (2019) finds evidence of depressive effects of the domestic EPU on exchange rates movements in EME. Therefore, a special focus on the ERV behavior in EME to both domestic and foreign EPU is worth noting.
} 
sensitivity of the ERV to the EPU. Using the recent Panel VAR (PVAR hereafter) methodology of Abrigo and Love (2016), our paper is not only the first to use a panel framework (to the best of our knowledge) but also one of the rare relying on VAR models to deal with ERV-EPU nexus ${ }^{4}$. Numerous reasons make this methodology a well suited tool for that purpose. First, it allows to account for the variables interactions and to capture market interdependences. So, why such issues could be of interest? On the one hand, in a globalized economy, a shock from one country can easily spill to other countries/markets. As it is also the case of the EPU international transmission (Jiang, 2019 among others), a PVAR set might help better understand such spillovers given its ability to account for international transmission of shocks (Canova and Ciccarelli, 2012). One the other hand, beyond the impacts running from the EPU to the ERV, the literature provides significant evidence on the ability of the EPU in a given country to predict the path of EPUs abroad (Gupta and Sun 2020; Jiang et al. 2019) ${ }^{5}$. Additionally, we assume that higher currency fluctuations imply government intervention which could translate into policy uncertainty. Hence, we conjuncture that a VAR setting might potentially (i) provide a novel insight regarding the endogenous linkage among these variables and (ii) be more relevant than single-equation models which could suffer from serious endogeneity biases resulting in possible misleading results ${ }^{6}$. Second, our procedure interestingly offers the possibility to simulate impulse response functions (IRFs) conventionally used to analyze the size and the sign of shocks propagation but also to appreciate the contribution of each shock to the ERV using the forecast error variance decomposition (FEVD).

In what follows, Section 2 describes the data and the econometric framework. Section 3 reports the main findings. Section 4 deals with robustness issues. Finally, Section 5 offers some concluding remarks.

\footnotetext{
${ }^{4}$ Notable exceptions are Nilavongse et al. (2020) and Beckmann and Czudaj, (2017) relying on time series VAR models to investigate the effects of the EPU on exchange rates returns and forecast errors.

${ }^{5}$ For instance, Gupta and Sun (2020) find significant evidence of a predictive ability of wide array of EPUs in emerging and developed countries on BRIC's EPU.

${ }^{6}$ Panel data models are likely to exhibit high cross-sectional dependence in the errors. This arises when countries in the panel respond not only to their own specific shocks but also to common shocks across the other panel members.
} 


\section{Data and Econometric framework}

Our study is conducted on a monthly basis for 8 EME: Singapore, China, Chile, India, Korea, Russia, Brazil and Mexico and includes 4 variables: the ERV, the domestic and foreign EPU, and the domestic output. While the sample covers the period from January 2003 through December 2018, the starting date is dictated by the data availability to ensure a balanced panel structure. Our sample interestingly englobes turmoil phases that are likely to increase the EPU: the collapse of Lehman Brothers (2008), the global financial crisis (2008-2009), the loss of the AAA sovereign rating of the US for the first time of its history (summer 2011), the mid-2014 oil price decline and the Sino-American trade conflict (2018).

The exchange rates examined are the daily spot rates of the domestic currencies against the US dollar and are retrieved from DataStream ${ }^{7}$. Their monthly standard deviation is computed to account for the ERV for each country. The domestic and foreign EPU's are the Baker et al. (2016)'s News-based indexes obtained from www.policyuncertainty.com. This index is a monthly coverage of Newspapers text search of articles including at least one term related to three categories (i) economy/economic, (ii) uncertainty/uncertain and (iii) policy (e.g. legislation, deficit, regulation etc.). As a proxy for the foreign EPU, we use the US-EPU since it is a benchmark of the international policy uncertainty (Das and Kumar, 2018) ${ }^{8}$. Furthermore, as a measure of output, we use the Industrial Production Index (IPI) drawn either from DataStream or from the OCDE database. This choice is mainly due to the unavailability of the Gross Domestic Product (GDP) on a monthly basis. At a general level, the use of IPI is not a challenging issue as it remains "a very good proxy" of real GDP (Fontaine et al. 2018). Finally, all our series are transformed in logarithm form.

In Equation 1, we describe the estimated PVAR that associates the panel data approach allowing unobservable individual heterogeneity to VAR models assuming the endogeneity of all the variables (Love and Zicchino, 2006).

\footnotetext{
${ }^{7}$ We select SGD/USD; CNY/USD; KRW/USD; BRL/USD; MXN/USD; CLP/USD; INR/USD and RUB/USD exchange rates respectively for Singapore, China, Korea, Brazil, Mexico, Chile, India and Russia.

${ }^{8}$ Note that a measure of global economic policy uncertainty (GEPU hereafter) is available from Baker et al. (2016). This measure is a GDP-weighted average of national EPU for 21 emerging and developed countries. It is possible that the GEPU provides information beyond the US-EPU, however it is main drawback is that it includes each country's own EPU. Therefore, we make the choice to use the GEPU as an alternative measure of foreign EPU in our robustness task.
} 
$Z_{i t}=U_{i}+\sum_{j=1}^{p} A_{j} Z_{i t-j}+\mu_{i t}$

, where $Z_{i t}$ is a $4 * 1$ vector of endogenous variables discussed above and $A$ is a $4 * 4$ coefficient matrix. The optimal lag $p$ is chosen to minimize information criteria. $U_{i}$ are vectors of country fixed effects that account for individual heterogeneity in the levels of the variables, and $\mu_{i t}$ are disturbance terms. $i$ and $t$ denote temporal (month) and individual (country) dimensions respectively.

One of the advantages of using the PVAR methodology is to explicitly introduce fixed effects which means that (i) each country in the sample can have a specific level of each variable used and (ii) the fixed effect can potentially capture other invariant factors (e.g. exchange rate regimes, country size, financial regulation etc). However, estimation biases may occur since the fixed effects are likely to be correlated with regressors that contain lagged dependent variables (Love and Zicchino, 2006). In such a circumstance, it is necessary to eliminate the fixed effects based on the "Helmert" method commonly used for that purpose ${ }^{9}$. In doing so, we preserve the orthogonality between the transformed variables and the lagged regressors which are used to instrument the VAR dynamics. Finally, the estimation is conducted using the Generalized Method of Moments (GMM). Then, we check the stability condition via modules of each eigenvalues of the estimated models. The results reported in Figure A.1 in the Appendices confirm that all eigenvalues are inside the unit circle. Consequently, the estimated PVAR specification fully satisfies the stability condition.

Moreover, an important advantage of the PVAR models is to allow producing the orthogonalized impulse response functions. These functions capture the effects of one variable to another endogenous variable when keeping the other variables constant (this is what is known as an orthogonal shock). Once all the coefficients of the PVAR model have been estimated the confidence bands of the orthogonalized IRFs are computed via Monte Carlo simulations as initially developed by Love and Zicchino (2006) and extended in Abrigo and Love (2016). To this end, we use the variance covariance matrix and the estimated coefficients from the PVAR to randomly build a draw of the VAR coefficients. Hence, the 5th and 95th percentiles are generated by replicating this procedure 1000 times in such a way the confidence intervals of

\footnotetext{
${ }^{9}$ The "Helmert" procedure removes the mean of the future observation available in each country-year.
} 
the IRFs are obtained. Nevertheless, the variance-covariance matrix is unlikely to be diagonal (Love and Zicchino, 2006). Accordingly, preserving the orthogonality of the residuals is essential in order to isolate shocks to one of the variables in the VAR system. In this case, a usual convention is to adopt a Cholesky decomposition of the variance-covariance matrix of the residuals i.e. transforming the VAR in a recursive form for an identification purpose. The Cholesky identification assumes that the variables enter the VAR system according to an ascending degree of endogeneity. Specifically, when a variable $\mathrm{x}$ appears earlier in the system and a variable $\mathrm{y}$ appears later, this means that $\mathrm{x}$ is exogenous with respect to $\mathrm{y}$ in the short run (Love and Zicchino, 2006).

Our identification assumption of structural shocks is based on Cholesky decomposition that closely follows the bulk of the literature ${ }^{10}$. We assume that the bloc of domestic variables can be affected by the US-EPU both contemporaneously and with a one-period delay. However, the US-EPU is able to react to domestic variables only with a lag. Within the bloc of domestic variables, the output is on the one hand assumed to exert an instantaneous effect on the ERV and the EPU as well as with a lag. On the other hand, it reacts to both variables only with a oneperiod delay. In order to constraint the exposure of the domestic EPU to the macroeconomic innovations, it is ordered last in the VAR (Colombo, 2013). To briefly sum up, the following ordering of the variables is retained [US-EPU, domestic output, ERV, and domestic EPU].

\section{Findings and discussion}

Prior to the estimation we have undertaken a preliminary analysis. The corresponding results are reported in the Table.1. Firstly, we conduct the Levin-Lin-Chu (2002) $1^{\text {st }}$ generation unit root test. As can be seen in Table 1, the results indicate the stationarity of all the variables used here. Second, we implement the Pesaran (2004) CD test in order to check for the cross-sectional dependence (the null hypothesis assumes no cross-sectional dependence). The results clearly support the rejection of the null hypothesis. On the one hand, the existence of cross-sectional correlation in the EME for our sample suggests that they are probably displaying similar macroeconomic policies features. Besides, such a property supports the adequacy of using a panel data framework in our study.

\footnotetext{
${ }^{10}$ The Cholesky decomposition means that the variables listed earlier in the VAR affect the following variables instantaneously and with a one-period delay. By contrast, the variables that come later exert an impact on previous variables only with a lag (Love and Zicchino, 2006). Overall, the ordering of the variables follows a decreasing order of exogeneity. Broadly, our Cholseky decomposition is closely related to recent papers dealing with uncertainty transmission. Examples include Fontaine et al. (2018), Colombo, (2013) among others.
} 
Such a result conducted us to check for the presence of unit roots relying on the $2^{\text {nd }}$ generation panel unit root test of Pesaran (2007). Assuming cross sectional dependence, this test highlights again the stationarity of all the considered variables ${ }^{11}$.

\section{Table.1 Preliminary Analysis}

\begin{tabular}{llll}
\hline Variables & \begin{tabular}{l}
$\mathbf{1}^{\text {st }} \begin{array}{l}\text { generation panel unit root } \\
\text { test of Levin-Lin-Chu }(\mathbf{2 0 0 2})\end{array}$ \\
\hline ERV
\end{tabular}$-13.98 * * *$ & $25.84 * * *$ & $\begin{array}{l}\mathbf{2}^{\text {nd }} \text { generation panel unit root test } \\
\text { of Pesaran (2007) }\end{array}$ \\
US-EPU & $-10.51 * * *$ & $73.32 * * *$ & $-5.25 * * *$ \\
EPU & $-7.57 * * *$ & $20.72 * *$ & - \\
Output & $-5.20 * * *$ & $30.94 * * *$ & $-5.08 * * *$ \\
GEPU & $-5.64 * * *$ & $73.32 * * *$ & $-2.70 * * *$ \\
\hline
\end{tabular}

Note: this table summarizes the obtained results of the $1^{\text {st }}$ and $2^{\text {nd }}$ generation panel unit root tests, and the crosssectional dependence test. GEPU indicates the global EPU index used for the robustness check purpose. ** and *** denote statistical significance at 5 and $1 \%$ levels respectively.

Moving now to the PVAR framework, two lags are selected as they were found to be optimal according to the selected information criteria. We report the corresponding results in Table. $2^{12}$.

Table 2. Optimal lag selection

\begin{tabular}{llll}
\hline Lags & HQ & SIC & AIC \\
\hline $\mathbf{1}$ & -143.15 & 111.75 & 16.77 \\
$\mathbf{2}$ & -174.01 & -4.07 & -67.39 \\
$\mathbf{3}$ & -85.01 & -0.03 & -31.69 \\
\hline
\end{tabular}

Note: this table illustrates the results of the information criteria considered in order to properly choose the lags to include in the VAR system. HQ, SIC and AIC refer respectively to HannanQuinn, Schwarz and Akaike information criteria.

Once the estimated coefficients of the PVAR model obtained, the orthogonalized IRFs are generated. The Figure.1 displays the IRFs that particularly plot the US-EPU spillover to EME. We find that a positive US-EPU shock (i) foreshadows both ERV and domestic EPU increase and (ii) has no significant effect on the domestic output. However, our results interestingly support significant indirect effects of the US-EPU on the EME activity. Firstly, we find that an

\footnotetext{
${ }^{11}$ Note that the Pesaran (2007) test is not able to provide results with respect the US-EPU and GEPU (robustness check) since the same variable is used for all the countries in the sample. We assume that these two variables are stationary in level based on the Levin-Lin-Chu (2002)'s test.

${ }^{12}$ To perform this methodology, the optimal lag selection is a crucial step. We make the choice of initially considering 3 lags since having a higher number of lags generates a loss of degree of freedom. This may result in over-parametrization. The result reported in this Table unanimously suggests 2 lags for the endogenous variables since it broadly minimizes the 3 information criteria. Besides, additional tests (not reported here, but available upon request) confirm that all usual assumptions on the residuals are also verified.
} 
ERV's increase significantly translates into an output contraction ${ }^{13}$. Secondly, combining this result with the observed positive US-EPU effects on the ERV, we emphasize the ERV role as a transmission mechanism of the negative US-EPU spillovers to the EME economic outlook. Accordingly, we conjecture that countercyclical current accounts and exports of EME (Bhattarai et al. 2019) could be more complicated with higher ERV induced by the foreign EPU. Such an effect leads to an aggregate supply decrease i.e. an output contraction. Overall, we support the role of (i) the US economy as a net transmitter of policy changes (Jiang et al. 2019), (ii) the US-EPU as negative foreign aggregate demand disturbances.

\section{Figure.1 US-EPU shock spillover to EME}
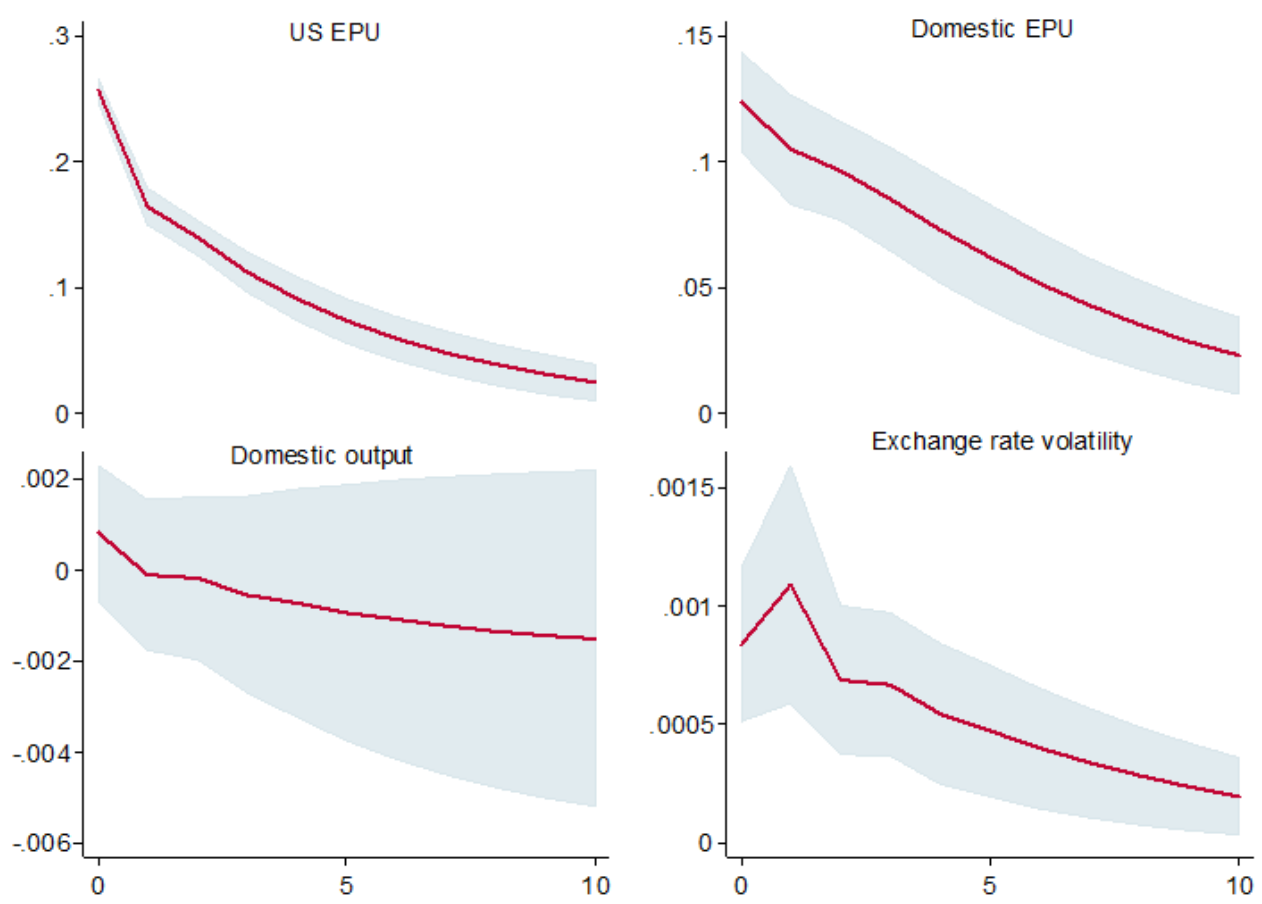

This Figure plots the orthogonalized impulse response of all the endogenous variables to a one standard deviation shock of the US-EPU. The red line presents the response of each variable. The bluish-gray boxes are the $95 \%$ confidence intervals constructed via Monte-Carlo simulations with 1000 replications. Periods are months.

Let us now discuss the domestic EPU shock effects on all variables ( $C f$. Figure 2). Our findings show a significant rise of the ERV following an unanticipated positive change of the domestic EPU, which is consistent with previous works (Chen et al. 2019; Bartsch, 2019). It is recognized that exchange rates movements are altered through fundamentals expectations (Beckmann and Czudaj, 2017) and economic policies changes (Alesina et al. 1997). Naturally, a higher EPU level leads to an increase of fundamentals expectations. As a result, currencies exhibit an

\footnotetext{
${ }^{13}$ Results are available in Figure A. 2 in Appendix.
} 
increased volatility (Krol, 2014). We also show that an unanticipated increase of the ERV generates a positive change in domestic EPU ( $C f$. Figure. A.2 in Appendices) ${ }^{14}$. A candidate explanation is that a higher ERV is generally perceived as bad signal to economic conditions. As a way to face such situation, policy makers might undertake several policy interventions (monetary policy actions, for instance). Consequently, policy uncertainty increases.

In addition, as Nilavongse et al. (2020), we find no evidence of a significant output response to the domestic EPU shock. Interestingly and perhaps surprisingly, we show that the US-EPU is positively responsive to the EME-EPU. Thus, we provide novel insights into EPU international spillovers and take a step further from studies supporting the prominent influence of the US on EME (Bhattarai et al. 2019). Therefore, we suggest that the US economy is not immune to a negative international policy shock. Even if the US is generally perceived as a net exporter of EPU (Klößner and Sekkel, 2014), we show that it also appears as an importer of such an uncertainty. Relatedly, we suggest an important role of the EME as an international policy uncertainty exporter. This can particularly make sense given the Sino-American trade tensions, for instance. Finally, we find that a favorable economic outlook in EME (an increase in output) results in a higher US-EPU. Such a result implies that US decision makers regard favorable EME conjuncture as valuable information that may alter their economic decisions. As an inevitable product of the government's policy making process, the US-EPU would naturally increase $^{15}$.

\footnotetext{
${ }^{14}$ The bidirectional positive relationship between ERV and domestic EPU strengthens our intuition regarding their endogenous linkage ( $C f$. introduction).

${ }^{15}$ Given that we rely on PVAR, we have chosen to be parsimonious in the baseline specification since a high number of variables reduce degrees of freedom. Nonetheless, we have also estimated our specification augmented with the US output (to control for US macroeconomic conditions), and domestic short-term interest rates (to control for monetary effects). The variables are introduced in the following order: US output, US-EPU, domestic output, short term interest rates, exchange rate volatility, domestic EPU (see for example, Fontaine et al. (2018); Colombo et al. (2013)). Interestingly, our evidence highlighted above remains unchanged. Results are not reported here to save space but are available from the corresponding author upon request.
} 
Figure 2. Effects of the local EPU shock in EME
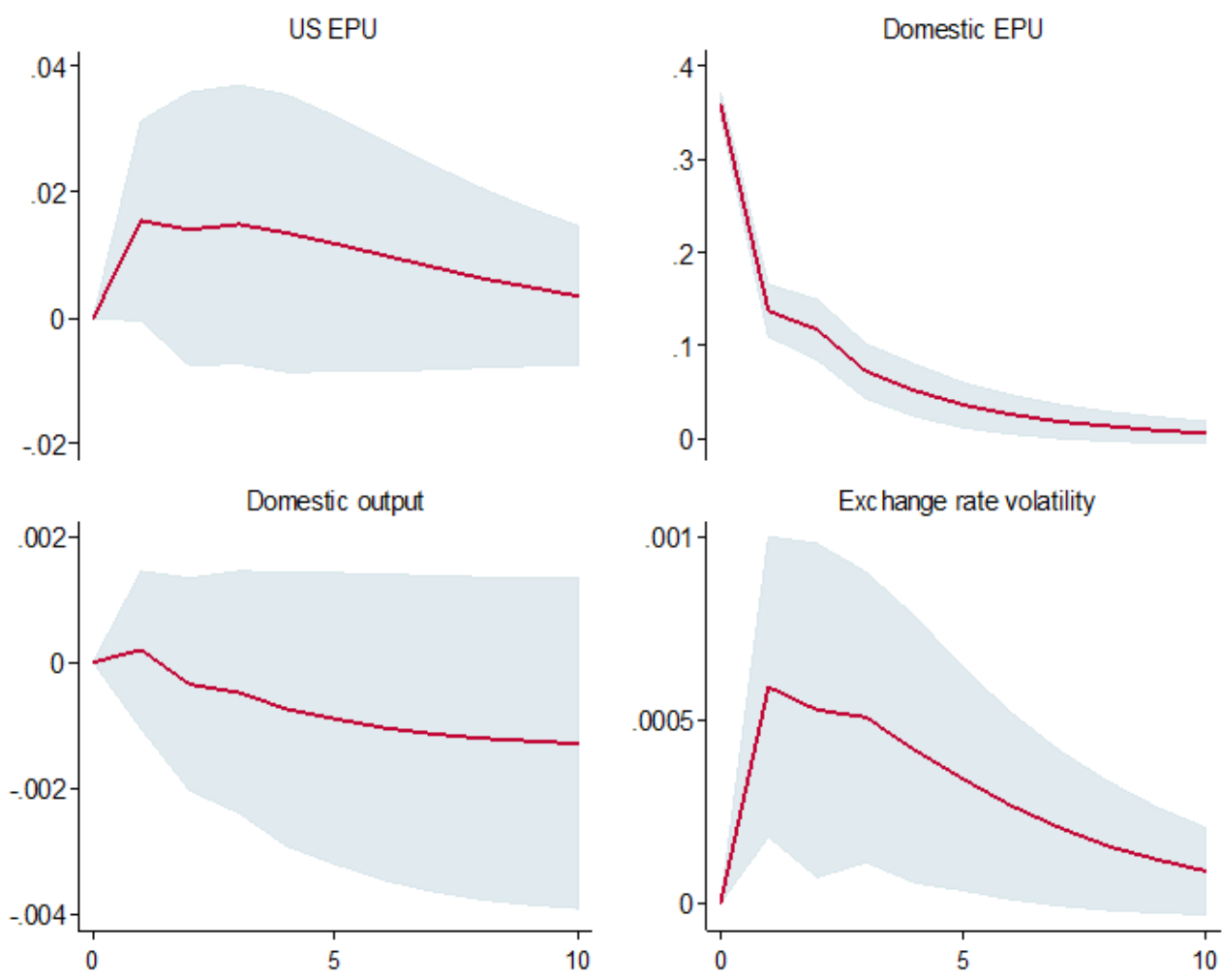

This Figure plots the orthogonalized impulse response of all the endogenous variables to one standard deviation shock of the domestic EPU. The red line presents the response of each variable. The bluish-gray boxes are the $95 \%$ confidence intervals constructed via Monte-Carlo simulations with 1000 replications. Periods are months.

Table 3. Forecast Error Variance Decomposition results

\begin{tabular}{|c|c|c|c|c|c|c|c|c|c|c|c|c|c|c|c|c|}
\hline$h$ & \multicolumn{4}{|c|}{ A. ERV } & \multicolumn{4}{|c|}{ B. EPU } & \multicolumn{4}{|c|}{ C. Output } & \multicolumn{4}{|c|}{ D. US-EPU } \\
\hline & ERV & USEPU & EPU & Output & ERV & USEPU & EPU & Output & ERV & USEPU & EPU & Output & ERV & USEPU & EPU & Output \\
\hline 12 & 89.9 & 6.9 & 2.6 & 0.4 & 3.2 & 18.9 & 74.6 & 5.9 & 5.1 & 0.2 & 0.1 & 94.5 & 0.1 & 86.6 & 3.1 & 10.0 \\
\hline 24 & 89.0 & 6.9 & 2.6 & 1.3 & 3.4 & 17.4 & 65.6 & 13.4 & 6.3 & 0.4 & 0.2 & 92.9 & 1.0 & 74.0 & 2.7 & 22.2 \\
\hline 36 & 88.3 & 6.9 & 2.6 & 2.0 & 3.6 & 16.3 & 61.5 & 18.4 & 6.7 & 0.5 & 0.2 & 92.3 & 1.7 & 66.3 & 2.4 & 29.4 \\
\hline
\end{tabular}

This Table reports the FEVD results highlighting the fraction of the forecast variance of row variables (A, B, C and D boxes) attributable to innovations in columns variables. The first column " $\mathrm{h}$ " refers to the forecast horizon i.e. 12 months, 24 months and 36 months.

From the FEVD analysis in Table.3, we clearly observe greater relevance of the US-EPU over the local EPU in explaining the ERV. Combined, both shocks explain nearly $10 \%$ of the ERV variance and their shares remain unchanged along all forecast horizons. Such a result strengthens our evidence that alongside domestic variables, the US-EPU is a crucial influential factor of EME currencies. Contrary to previous papers but in line with our IRFs, we show that 
the US-EPU contribution to the output fluctuation is surprisingly weak. Furthermore, our FEVD highlight that the short-run domestic EPU fluctuation is driven to a great extent (nearly 25\%) by US-EPU (18.9\%) and output shocks (5.9\%). The contribution of US-EPU (output) shocks slightly (considerably) decreases (increases) with the forecast horizon ${ }^{16}$. Specifically, the role of the US-EPU (output) shocks is more pronounced in the short (long) run. Interestingly, we also observe that the fraction of the EME output to explain the US-EPU fluctuations rises along forecast horizons to achieve one third in the long-run. This not only echoes again our IRFs simulations but also gives support to our conclusion regarding the EME economic outlook as a source of US economic changes.

\section{Robustness checks}

To investigate the robustness of our findings, we have undertaken several sensitivity analyses. Specifically, we check if our results are altered if we (i) re-estimate IRFs based on an alternative lag structure, (ii) use the Global EPU (GEPU) index as an alternative proxy of the foreign EPU ${ }^{17}$ and (iii) cut Singapore and China out of our sample since they have adopted different exchange regimes compared to the other countries ${ }^{18}$. Our sensitivity findings confirm that the overall dynamics of our PVAR are immune to all modifications ${ }^{19}$. Therefore, we interestingly provide strong and robust evidence.

\footnotetext{
${ }^{16}$ Our finding is closely related to Gupta and Sun (2020) which show for the BRIC that models including foreign EPU provide better forecasts than those with domestic EPU alone.

${ }^{17}$ This variable enters the PVAR system in logarithmic form and it is stationary in level (see Table 1) provides more details on the panel unit root result.

${ }^{18}$ According to the IMF (2018), the former (latter) adopt a soft pegged regime (managed floating) regime. The remaining countries adopt floating regimes.

${ }^{19}$ The sensitivity analysis results are detailed in Appendix B.
} 


\section{Conclusion}

In this paper we use the recent panel VAR methodology of Abrigo and Love (2016) that accounts in particular for variables' interaction, and cross-country lagged interdependencies to investigate the Exchange Rate Volatility (ERV) response to Economic Policy Uncertainty (EPU) shocks, which is, to our best knowledge the first attempt in this context. Our results suggest that the ERV in EME is sensitive to both domestic and foreign EPU. Such findings support the negative US uncertainty spillovers to macroeconomic activities abroad (e.g. Colombo, 2013) and complement this by showing that the ERV acts as a possible channel of such transmission. By showing that the US-EPU accounts more than the domestic EPU in explaining the ERV fluctuation, we provide novel insights into FOREX-EPU nexus which generally conclude that domestic activity (exchange rates) is more reactive to the global (domestic) EPU (Nilavongse et al. 2020). Assuming that such a difference is probably due to our procedure and specific context, we support the key role of markets cross sectional dependence when dealing with EPU implications. Then, it seems not suitable to generalize time series results and advanced economies or some major EME (e.g. China) findings to the whole emerging economies context.

Beyond the transmission of the policy uncertainty over the ERV, two important results emerge from our investigation. First, we provide evidence of a positive effect of the ERV increase on the domestic EPU. Second, another important finding is the responsiveness of the US-EPU to EME outlook. Hence, even though the US is perceived as a net exporter of EPU, it also imports such an uncertainty from EME.

Our findings have interesting implications to decisions makers and investors in EME. Picking sound economic policies and reducing the exposure to the US economic policy fluctuations is relevant for their future monitoring of exchange rate fluctuations. In addition, EME investors should incorporate domestic and abroad policy information in order to properly manage their exchange exposure and optimize portfolios allocation. On the US side, policy decisions makers' should probably monitor the EME macroeconomic conditions in order to predict their own EPU changes.

Finally, a nonlinear assessment of the ERV-EPU nexus is worth mentioning as a potential avenue for future researches. 


\section{References}

[1] Abid, A., 2019. Economic Policy Uncertainty and Exchange Rates in Emerging Markets: Short and Long Runs Evidence. Finance Research Letters. https://doi.org/10.1016/j.frl.2019.101378.

[2] Abrigo, M.R., Love, I., 2016. Estimation of Panel Autoregression in Stata. Stata journal. 16, 778-804.

[3] Arouri, M., Estay, C., Rault, C., Roubaud, D., 2016. Economic Policy Uncertainty and Stock Markets: Long-Run Evidence from the US. Finance Research Letters. 18, 136-141.

[4] Alesina, A., Roubini, N., Cohen, G.D., 1997. Political Cycles and the Macroeconomy. The MIT press, Cambridge.

[5] Baker, S., Bloom, N., Davis, S.J., 2016. Measuring Economic Policy Uncertainty. The Quarterly Journal of Economics.131, 1593-163.

[6] Balcilar, M., Gupta, R., Kyei, C., Wohar, M.A., 2016. Does Economic Policy Uncertainty Predict Exchange Rate Returns and Volatility? Evidence from a Nonparametric Causality-inQuantiles Test. Open Economic Review. 27, 229-250.

[7] Bartsch, Z., 2019. Economic Policy Uncertainty and Dollar-Pound Exchange Rate Return Volatility. Journal of International Money and Finance. 98, 102067.

[8] Beckmann, J., Czudaj, R., 2017. Exchange Rate Expectations and Economic Policy Uncertainty European Journal of Political Economy. 47, 148-162.

[9] Bhattarai, S., Chatterjee, A., Park, W.Y., 2019. Global Spillover Effects of US Uncertainty. Journal of Monetary Economics. https://doi.org/10.1016/j.jmoneco.2019.05.008.

[10] Bloom, N., 2009. The impact of Uncertainty shocks. Econometrica. 77, 623-685.

[11] Brogaard, J., Detzel, A., 2015. The Asset-Pricing Implications of Government Economic Policy Uncertainty. Management Science. 61, 3-18.

[12] Canova, F., Ciccarelli, M., 2012. ClubMed? Cyclical fluctuations in the Mediterranean basin. Journal of International Economics. 88, 162-175. 
[13] Chen L., Du, Z., Hu, Z., 2019. Impact of Economic Policy Uncertainty on Exchange Rate Volatility of China. Finance Research Letters. https://doi.org/10.1016/j.frl.2019.08.014.

[14] Chen, S., Chou, Y., 2015. Revisiting the Relationship between Exchange Rates and Fundamentals. Journal of Macroeconomics. 46, 1-22.

[15] Christou, C., Gupta, R., Hassapis, C., Suleman, T., 2018. The Role of Economic Uncertainty in Forecasting Exchange Rate Returns and Realized Volatility: Evidence from Quantile Predictive Regressions. Journal of Forecasting. 37, 705-719.

[16] Colombo, V., 2013. Economic Policy Uncertainty in the US: Does it Matter for the Euro area? Economic Letters. 121, 39-42.

[17] Das, D., Kumar, S.B., 2018. International Economic Policy Uncertainty and Stock Prices Revisited: Multiple and Partial Wavelet Approach. Economic Letters. 164, 100-108.

[18] Fontaine, I., Razafindravaosolonirina, J., Didier, L., 2018. Chinese Policy Uncertainty Shocks and the World Macroeconomy: Evidence from STVAR. China Economic Review. 51, $1-19$.

[19] Gupta, R., Sun, X., 2020. Forecasting Economic Policy Uncertainty of BRIC Countries Using Bayesian VARs. Economic Letters. 186, 108677.

[20] Jiang, Y., Zhua , Z., Tiana, G., Nie, H., 2019. Determinants of Within and Cross-Country Economic Policy Uncertainty Spillovers: Evidence from US and China. Finance Research Letters. https://doi.org/10.1016/j.frl.2019.08.004.

[21] Klößner, S., Sekkel, R., 2014. International Spillovers of Policy Uncertainty. Economic Letters. 124, 508-512.

Krol, R., 2014. Economic Policy Uncertainty and Exchange Rate Volatility. International Finance. 17, 241-255.

[22] Levin, A., Lin, C.F., Chu, C.S.J., 2002. Unit Root Test in Panel Data: Asymptotic and Finite Sample Properties. Journal of Econometrics. 108, 1-24. 
[23] Love, I., Zicchino, L., 2006. Financial Development and Dynamic Investment Behavior: Evidence from Panel VAR. The Quarterly Review of Economics and Finance. 46, 190-210.

[24] Meese, R., Rogoff. K., 1983. Empirical Exchange Rate Models of the Seventies: Do they Fit out of Sample. Journal of International Economics. 14, 3-24.

[25] Nilavongse, R., Rubaszek, M., Salah Uddin, G., 2020. Economic Policy Uncertainty Shocks, Economic Activity, and Exchange Rate Adjustments. Economic Letters. 186, 108765.

[26] Pástor, L., Veronesi, P., 2012. Uncertainty about Government Policy and Stock Prices. Journal of Finance. 67, 1219-1264.

[27] Pesaran, M.H., 2004. General Diagnostic Tests for Cross Section Dependence in Panels. Cambridge Working Papers in Economics 0435.

[28] Pesaran, M.H., 2007. A simple Panel Unit Root Test in the Presence of Cross-Section Dependence. Journal of Applied Econometrics. 22, 265 - 312. 


\section{Appendices}

\section{Appendix A. The PVAR estimation}

Figure.A.1. Stability of the PVAR estimates

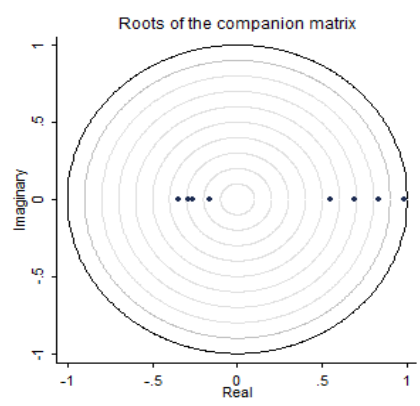

Figure A.2. IRFs for PVAR model

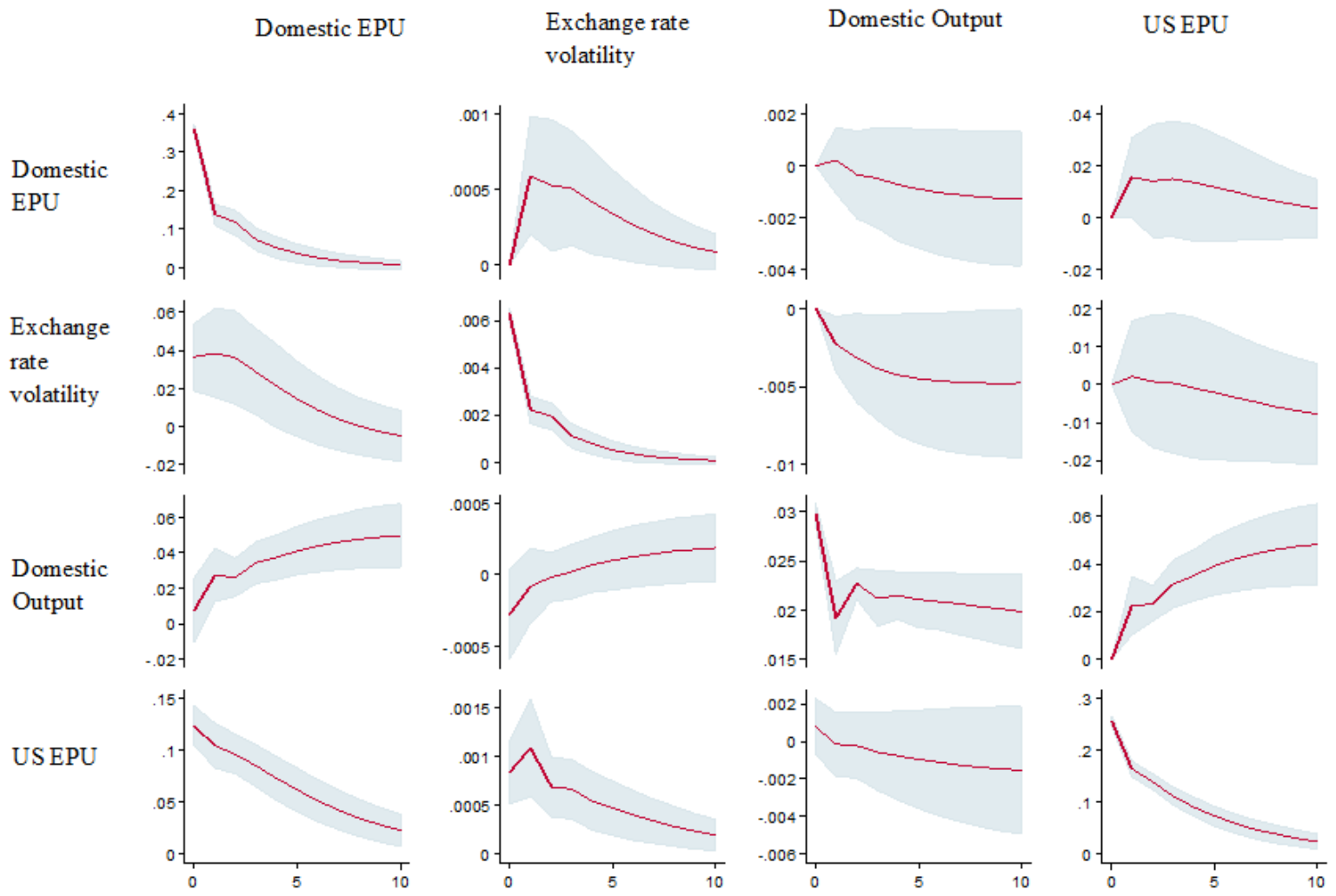

This figure plots the orthogonalized IRFs of all the variables to a positive one standard deviation shock of each variable in the PVAR system along with $95 \%$ error bands. The bluish-gray boxes are confidence intervals constructed via Monte-Carlo simulations with 1000 replications. Periods are months. Non-zero effects i.e. significant shocks impacts are observed when the zero line is outside of the corridor. 


\section{Appendix B. Robustness Check}

(i) Estimating the PVAR model with an alternative lag structure

Figure B.1. Stability of the PVAR model augmented with a lag

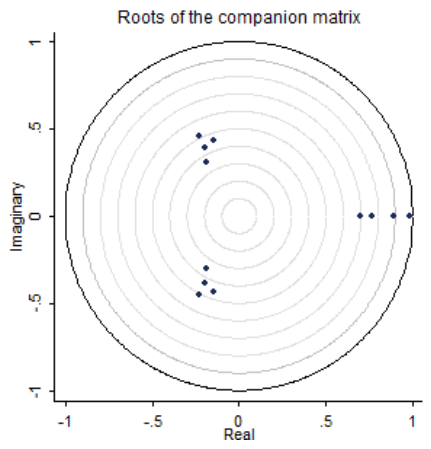

The results illustrated in Figure B.1 indicate the stability of the PVAR model with three lags

Figure B.2. Orthogonalized IRFs. Robustness Check (PVAR model augmented with a lag)

Domestic EPU

Exchange rate volatility
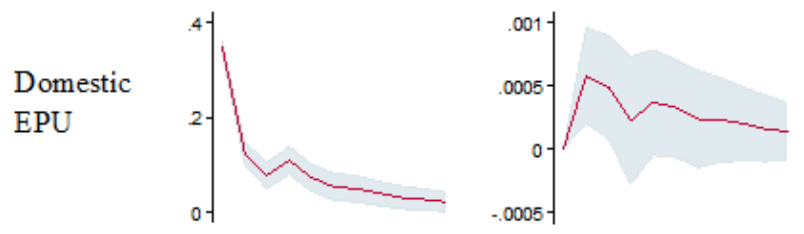

Domestic output

USEPU

Exchange

rate

volatility
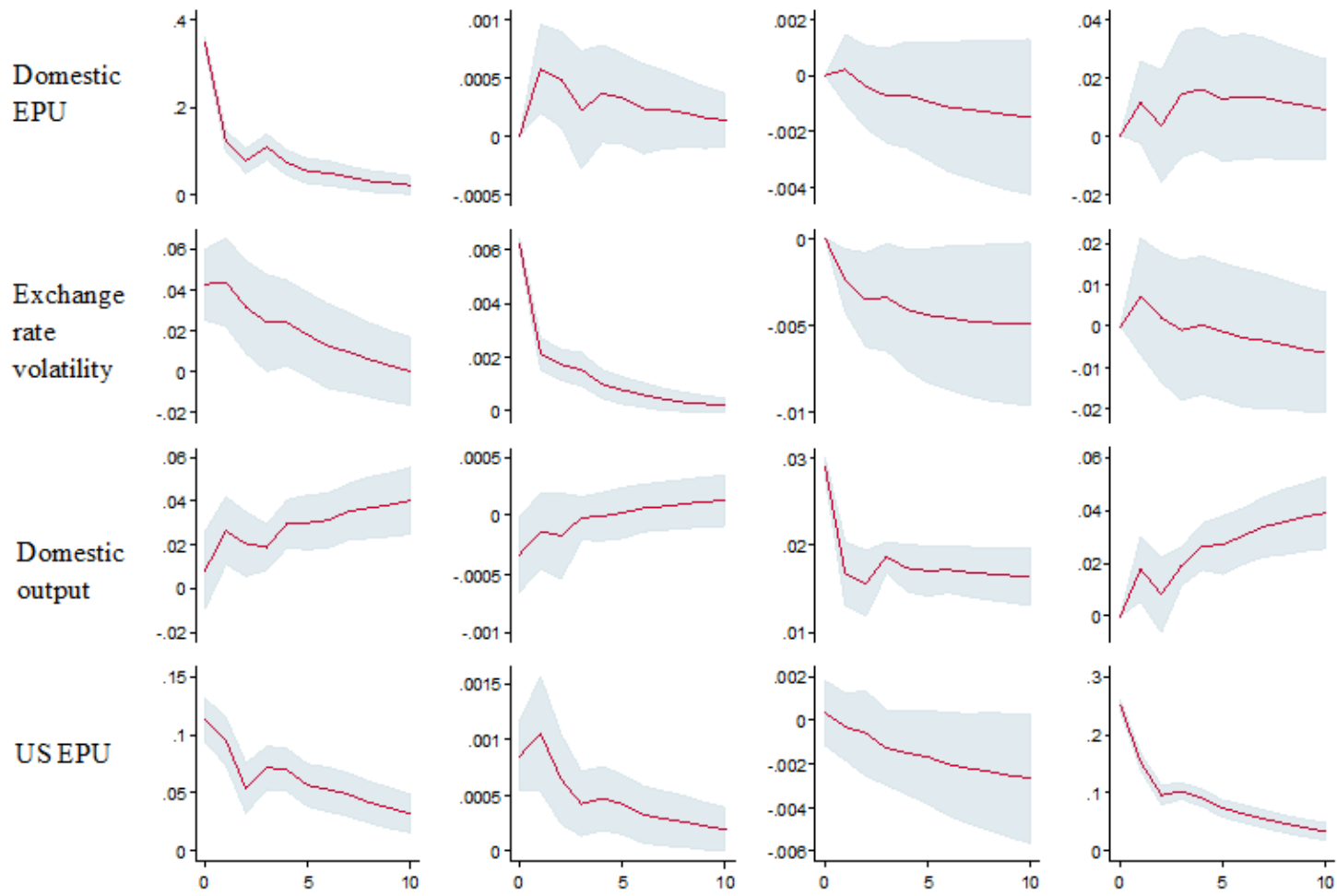

This figure plots the orthogonalized IRFs of all the variables to a positive one standard deviation shock of each variable in the PVAR system along with $95 \%$ error bands. These plots show the response of the column variable to an innovation on the row variable based on PVAR estimates with three lags. The bluish-gray boxes are confidence intervals constructed via Monte-Carlo simulations with 1000 replications. Periods are months. Nonzero effects i.e. significant shocks impacts are observed when the zero line is outside of the corridor. 
Figure B.3. Stability of the PVAR model with Global EPU (GEPU)

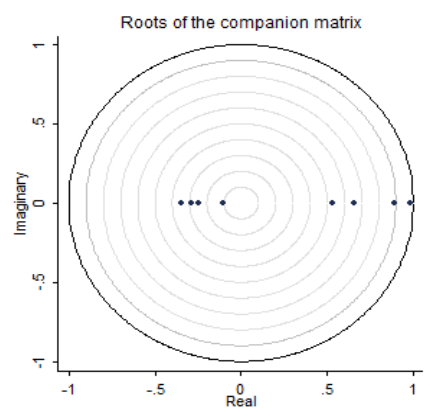

Our PVAR estimates using the GEPU are stable as highlighted in the Figure B.3.

\section{Figure B.4. Orthogonalized IRFs. Robustness Check (PVAR model with GEPU)}

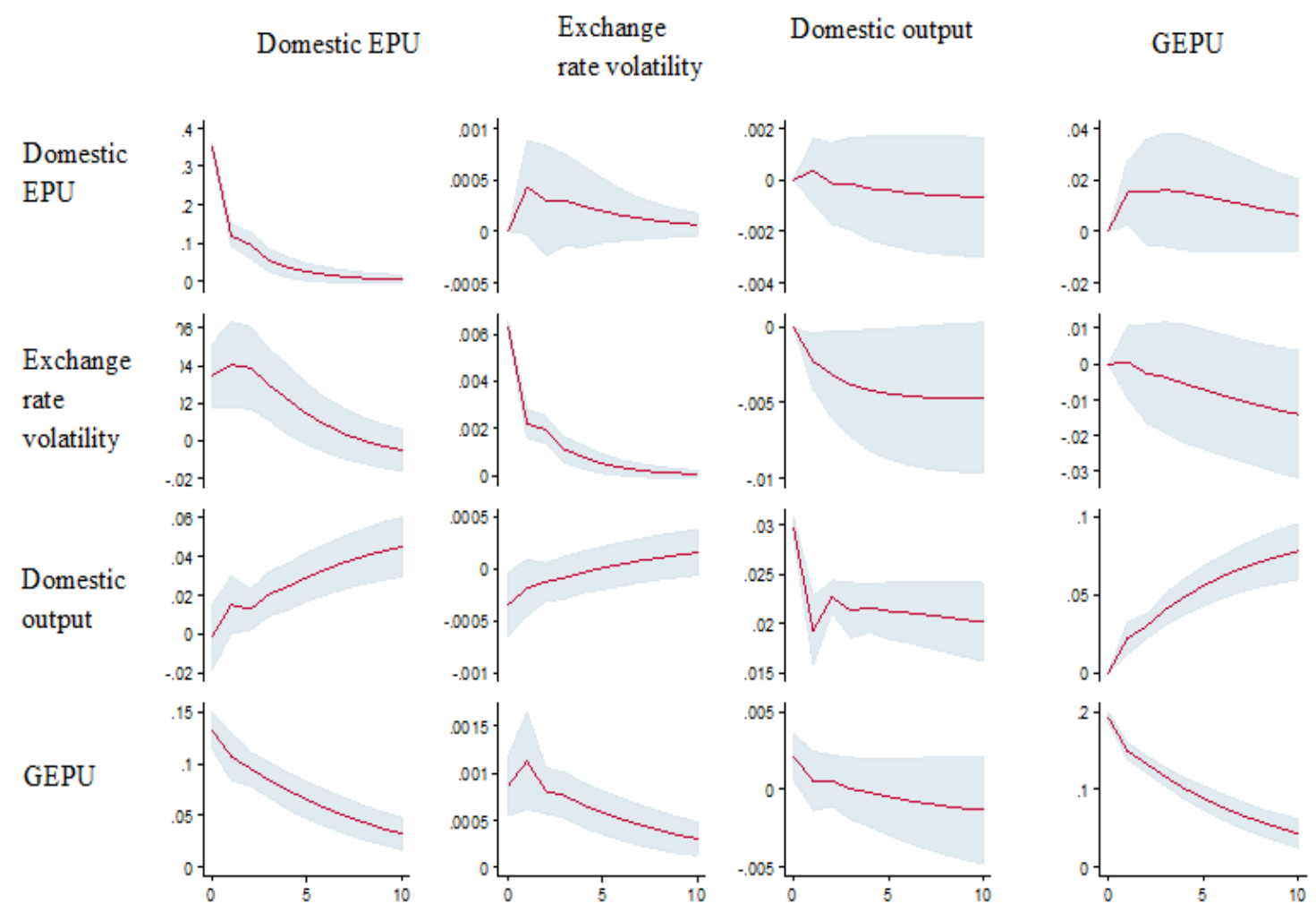

This figure plots the orthogonalized IRFs of all the variables to a positive one standard deviation shock of each variable in the PVAR system along with $95 \%$ error bands. These plots show the response of the column variable to an innovation on the row variable based on PVAR estimates when replacing the US-EPU by the GEPU. The bluish-gray boxes are confidence intervals constructed via Monte-Carlo simulations with 1000 replications. Periods are months. Non-zero effects i.e. significant shocks impacts are observed when the zero line is outside of the corridor. 
(iii) Estimating the PVAR model with a different sample

\section{Figure B.5. Stability of the PVAR model excluding Singapore and China from the sample}

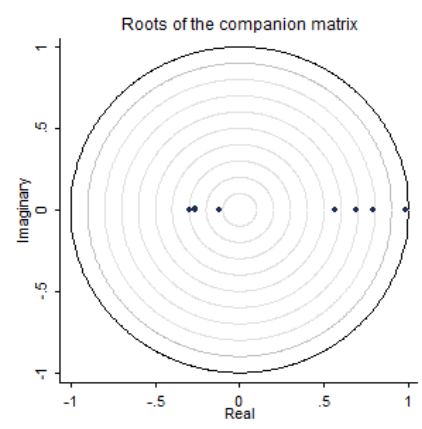

We drop both Singapore and China out of the sample and re-estimate our PVAR model. The optimal lag selection based on the three information criteria retained previously also provides indicative evidence of two optimal lags. Corresponding results are not reported here but are available on request. Regarding the stability condition, we can observe on figure C. 1 that eigenvalues are inside the unit circle indicating a strong stability of this alternative PVAR specification.

Figure B.6. Orthogonalized IRFs. Robustness Check (PVAR model excluding Singapore and China)

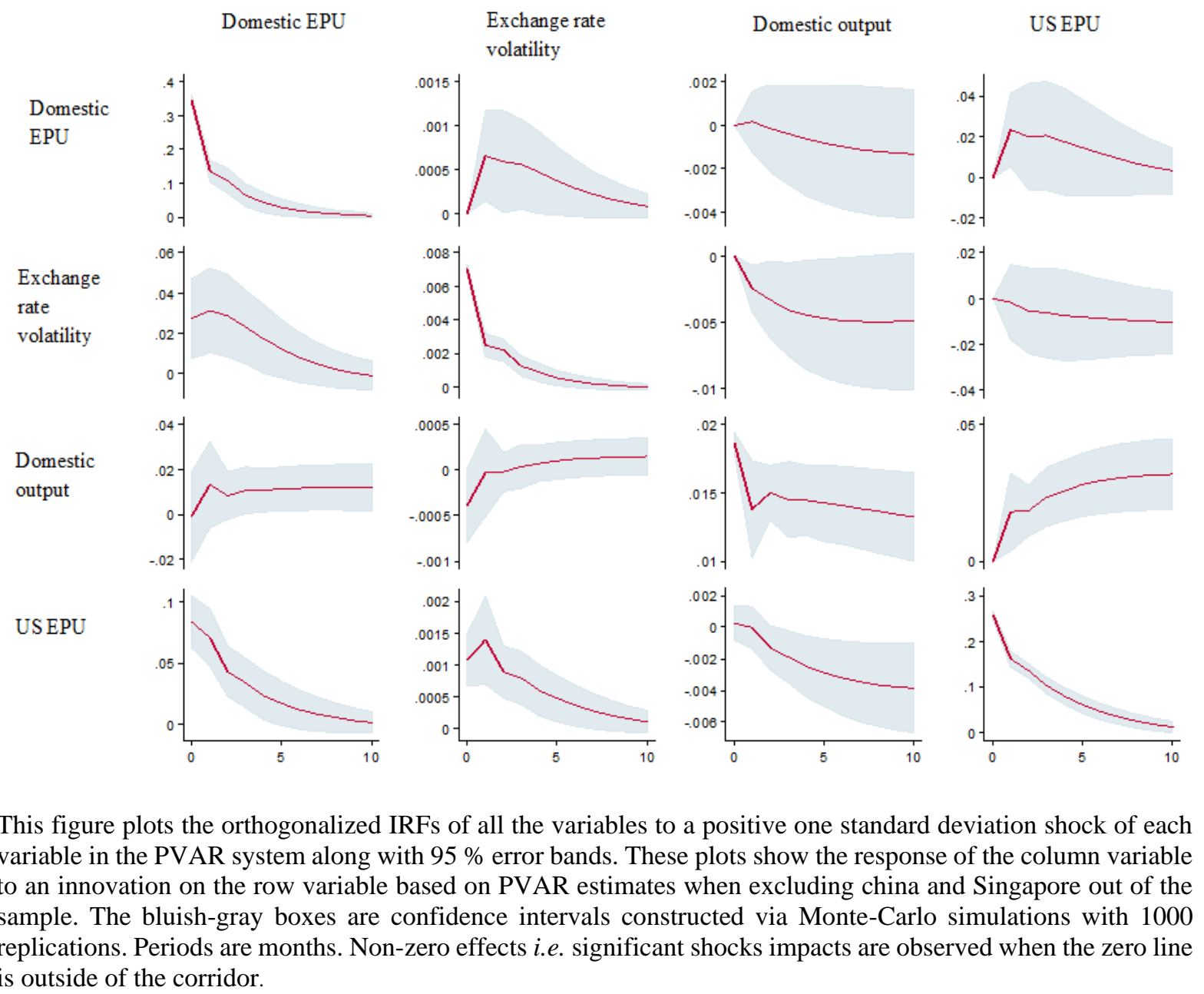

